\title{
MOLD METAL REACTIONS OF MAGNESIUM ALLOY AZ91E USING SF6 AND 3M NOVEC 612 AS PROTECTIVE GASSES IN INVESTMENT CASTING TECHNOLOGY
}

\author{
${ }^{1}$ Martin DYČKA, ${ }^{1}$ Martin JULIŠ, 'Lenka KLAKURKOVÁ, 'Lucie DYČKOVÁ, ${ }^{1}$ Pavel GEJDOŠ \\ ${ }^{1}$ Brno University of Technology, Central European Institute of Technology, Brno, Czech Republic, EU \\ martin.dycka@ceitec.vutbr.cz, martin.julis@ceitec.vutbr.cz, lenka.klakurkova@ceitec.vutbr.cz, \\ lucie.dyckova@ceitec.vutbr.cz, pavel.geidos@ceitec.vutbr.cz
}

https://doi.org/10.37904/metal.2020.3584

\begin{abstract}
In this article, the intensity of mold metal reactions between ceramic shell and magnesium alloy AZ91E is studied. The two possible protective gasses used for melt protection are studied - $\mathrm{SF}_{6}$ (sulphur hexafluoride) and 3M NOVEC 612. The scanning electron microscopy (SEM) with X-ray spectroscopy (EDS) were used for the analyses of the mold-metal reaction products on the interface between the magnesium alloy and the ceramic shell. Penetration of AZ91E into the ceramic shell was observed, thickness of mold-metal reaction products layer ranged from $0 \mu \mathrm{m}$ to $80 \mu \mathrm{m}$. The intensity of mold metal reaction is much higher on the outer surface than on the inner surface of the casting. The thicker layer of the fine zircon particles as the first layer of ceramic shell seems to lower the mold metal reactions intensity to minimum. While using $\mathrm{SF}_{6}$, the penetration of AZ91E into ceramic shell was observed, the corroded layer consists of Al-enriched phase with higher content of oxygen. The use of 3M NOVEC 612 as the protective gas led to formation of continuous MgO layer between the ceramic shell and the magnesium alloy, thickness of this layer was up to $60 \mu \mathrm{m}$ depending on the ceramic shell composition in the close surrounding area.
\end{abstract}

Keywords: Magnesium alloy AZ91, casting, mold-metal reactions, sulphur hexafluoride, 3M Novec 612

\section{INTRODUCTION}

In the recent years, the continuous pressure for the reduction of the green house gasses emissions in all means of transportation makes designers of transport vehicles to use higher portion of light weight materials. Many parts, commonly manufactured from steel, are being replaced by plastic, composites or light weight metal alloys, such as aluminum or magnesium alloys. Although the aluminum alloys are much widely used than magnesium alloys because of their lower cost, excellent corrosion resistance and easier processing, magnesium alloys are still increasingly used, because of their better combination of good mechanical properties along with lower weight in comparison with aluminum alloys [1]. Nowadays, the disadvantages of magnesium alloys have been lowered or even eliminated as the result of the development of new and highperformance magnesium alloys. The development of new processing techniques, which can significantly decrease manufacturing problems connected with its high reactivity with oxygen, caused the rapid increase of magnesium alloys used in automotive industry. This increase is however connected mostly with the use of die casting technology, which is suitable for the large scale production; while the application potential of magnesium alloys in the small series cast production areas, where die casting is too expensive, is still limited because of the problem of its high reactivity with oxygen and high shrinkage causing many kinds of casting defects.

The investment casting of magnesium alloys was for many years depended on using of Sulphur hexafluoride $\mathrm{SF}_{6}$ as a melt protective gas during casting. In 2019 European regulation no. 517/2014 has entered into force 
in Czech Republic, and the further use of $\mathrm{SF}_{6}$ in magnesium casting industry is prohibited [2]. There are only few alternatives to $\mathrm{SF}_{6}$ available on the market, which could be used as an alternative. One of the possible alternative is available in the market under trademark NOVEC 612 produced by $3 \mathrm{M}$ company. It is a fluorinated ketone dodecafluoro-2-methyl-3-pentanone $\left(\mathrm{CF}_{3} \mathrm{CF}_{2} \mathrm{C}(\mathrm{O}) \mathrm{CF}\left(\mathrm{CF}_{3}\right)_{2}\right.$, which is colourless liquid with boiling point around $50^{\circ} \mathrm{C}$. As like $\mathrm{SF}_{6}$, it forms thin protective layer of $\mathrm{MgF}_{2}$ on the surface of magnesium melt, creating a barrier between magnesium and surrounding oxygen [3]. There is a lack of published experimental work investigating the efficiency of melt protection during solidifying using NOVEC 612, especially in comparison with $\mathrm{SF}_{6}$. The main aim of this article is to provide these information.

\section{EXPERIMENTAL SETUP}

The mold-metal reactions were studied on magnesium alloy AZ91E alloyed with aluminum and zinc protected by $\mathrm{SF}_{6}$ and NOVEC 612 . The mold-metal reactions intensity was evaluated as a thickness of corroded layer between ceramic shell and magnesium casting. The ceramic shell had the same composition for all samples. As the first coat, fine zircon particles were used followed by coarse alumino-silicate back-up coats. Colloidal silica was used as a binder. Composition of ceramic shell is shown in Figure 1.

The protective gas was applied just before casting of liquid metal into ceramic shell preheated to $440{ }^{\circ} \mathrm{C}$, temperature of metal was $730^{\circ} \mathrm{C}$. Bottom filling technique was used.

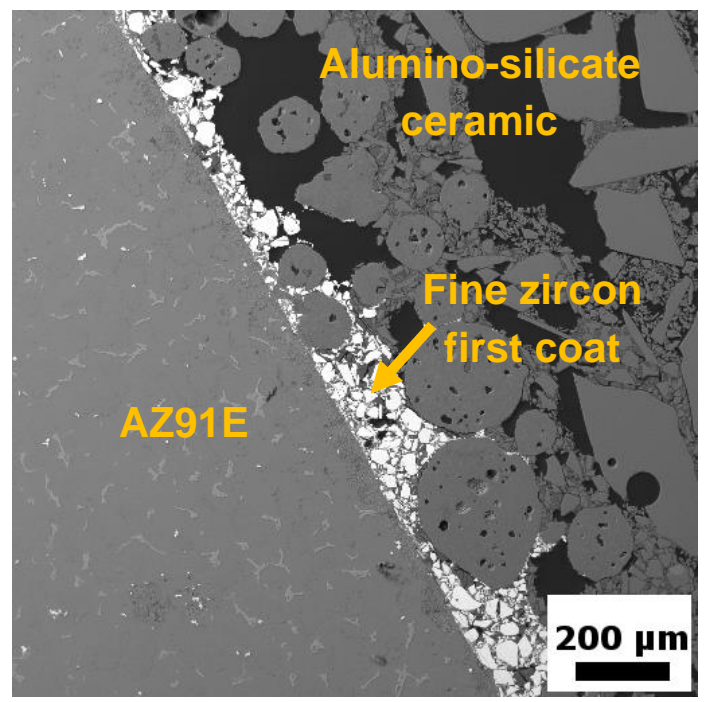

Figure 1 Ceramic shell composition close to magnesium alloy

The casted samples were cut and molded into resin to prepare metallographic samples. During preparation, standard grinding and polishing techniques were used using diamond suspensions with diamond size ranging from $9 \mu \mathrm{m}$ to $0.25 \mu \mathrm{m}$. As the final step, samples were etched using acetic-picric etchant.

Light microscopy (DSX510, OLYMPUS) and electron microscopy (LYRA3, TESCAN) were used to study the microstructure of all samples. EDS analyses were used for chemical analyses and phase identification.

\section{EXPERIMENTAL RESULTS}

\subsection{Mold metal reactions under protection of $\mathbf{S F}_{6}$}

Sulphur hexafluoride was used as a melt protective gas and was applied to the ceramic shell before pouring of liquid metal. There were observed some changes in the microstructure close to the surface of AZ91E alloy, but continuous oxide layer was not found on any sample. On the inner side of semicircular casting, where the 
oxygen penetration from ambient atmosphere was difficult, there were observed no traces of the mold metal reactions in corners, where the thicker layer of fine zircon particles was present (see Figure 2). On the walls from the inner side, some changes in the microstructure were observed (Figure 3), EDS analysis showed the enrichment of the surface layer with aluminum (Figure 4). These changes appeared together with the penetration of magnesium alloy into the ceramic shell as can be seen in Figure 3.

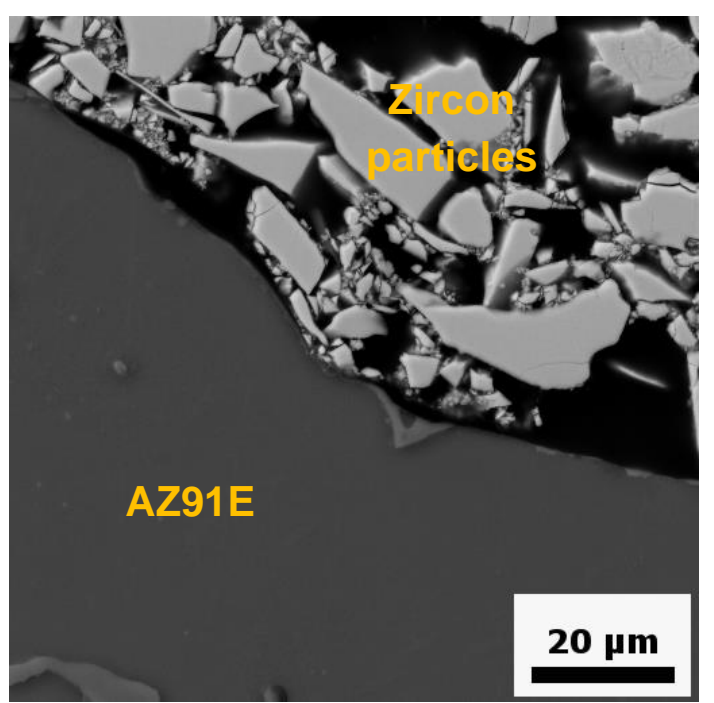

Figure 2 Mold metal reactions in the inner corner

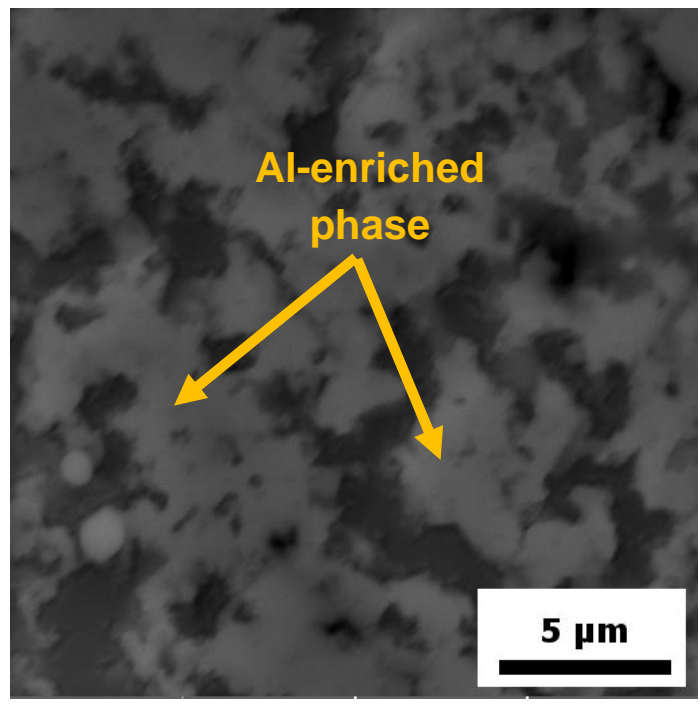

Figure 4 Detail of microstructure in the reacted area close to the surface (bright phase- Al enriched, dark phase- AZ91E nominal chemical composition).

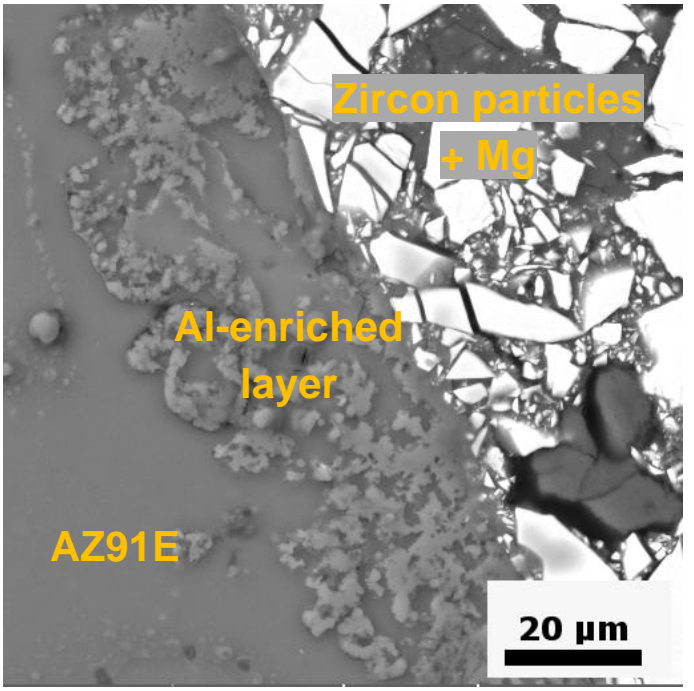

Figure 3 Mold metal reactions in the inner corner on the inner wall

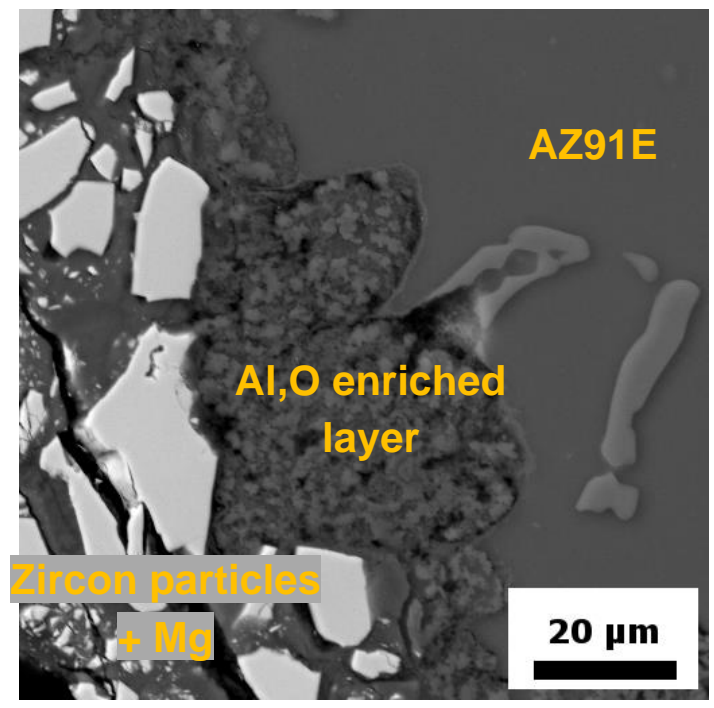

Figure 5 Interface between ceramic shell and magnesium alloy on the outer surface

The mold-metal reaction intensity on the outer surface of the same casting was much higher (Figure 5). In this case, the reaction products form continuous layer between magnesium alloy and ceramic shell, which was separated from magnesium alloy. The magnesium penetration into ceramic shell was much more extensive in comparison with the inner surface. EDS shows enrichment of aluminum as it was on the inner wall, but also in the addition the high enrichment with oxygen (Figure 6). 

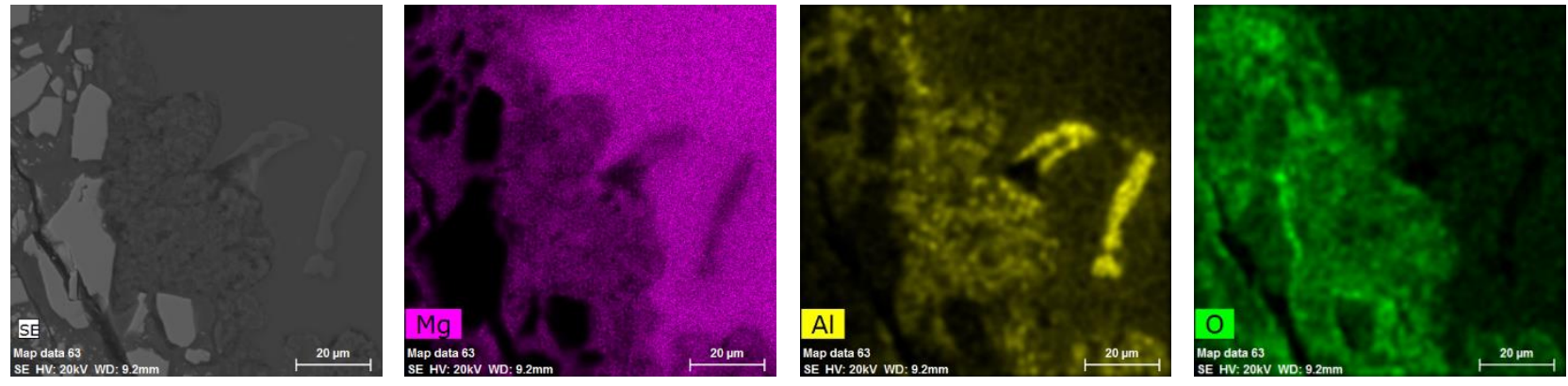

Figure 6 EDS results showing penetration of magnesium into ceramic shell and the enrichment of reacted layer with aluminum and oxygen

\subsection{Mold metal reactions under protection of NOVEC 612}

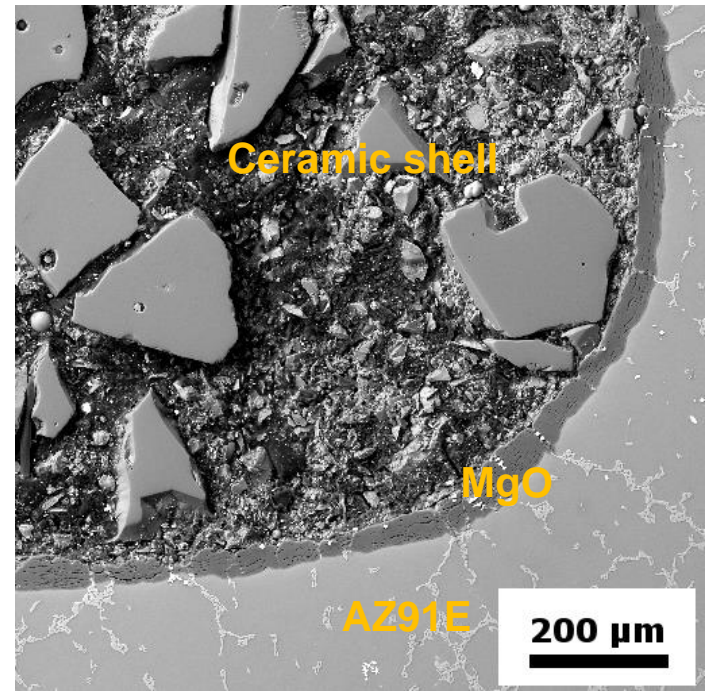

Figure 7 Oxide layer in the corner

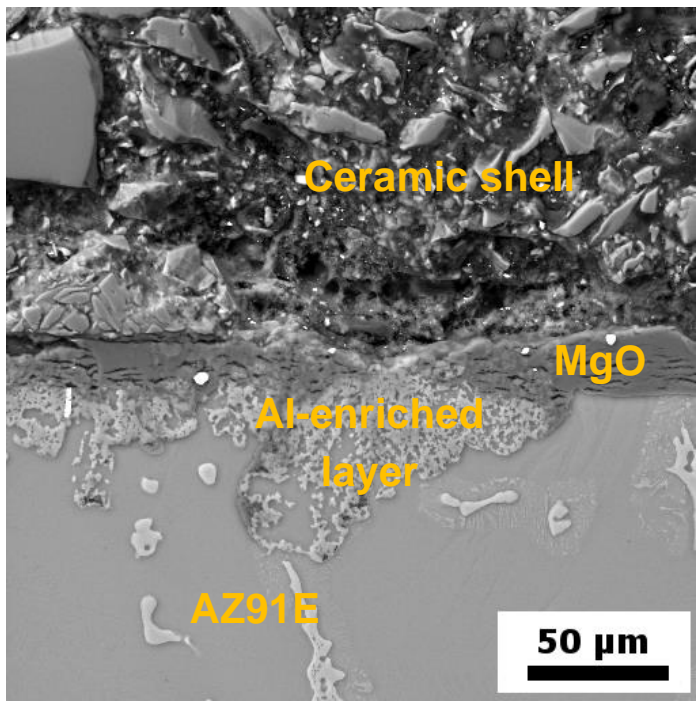

Figure 8 Oxide layer on the wall

When Sulphur hexafluoride was replaced by Novec 612 (both applied directly to the mold just before casting of liquid metal), the appearance of mold-metal reactions changed. On the interface between AZ91E and ceramic shell, the continuous layer of $\mathrm{MgO}$ was formed as can be seen in Figure 7 and Figure $\mathbf{8}$. Thickness of this oxide layer ranges from $10 \mu \mathrm{m}$ to more than $60 \mu \mathrm{m}$ in the most reacted areas. The formation of continuous oxide layer can appear alone or in combination with microstructure changes connected with the magnesium penetration into the ceramic shell and the enrichment of the surface layer with aluminum (Figure 9) as described when $\mathrm{SF}_{6}$ was used. In this case, thickness of MgO layer ranges from $5 \mu \mathrm{m}$ to $20 \mu \mathrm{m}$, total thickness of reacted layer is not higher than $80 \mu \mathrm{m}$.
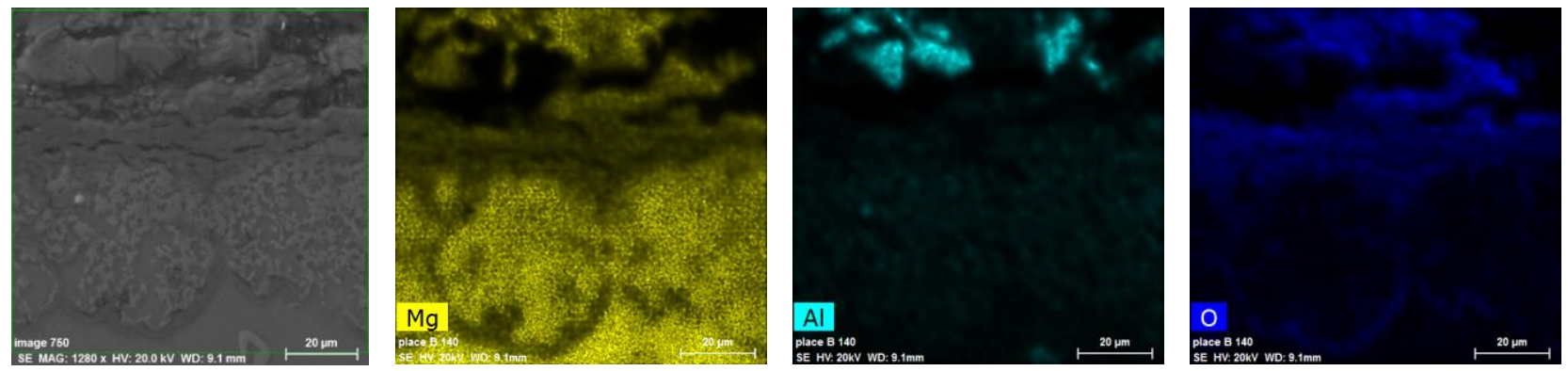

Figure 9 Oxide layer along with aluminium and oxygen enriched layer and the magnesium penetration into the ceramic shell 


\section{CONCLUSIONS AND DISCUSSION}

The mold-metal reaction intensity was found to be smaller with the use of $\mathrm{SF}_{6}$ as a protective gas, whereas with the use of NOVEC 612 , the reaction intensity was higher. When $\mathrm{SF}_{6}$ was used, the penetration of magnesium into the ceramic shell was observed together with the changes in microstructure close to the interface with the ceramic shell. The aluminum enrichment was found in this layer as a probably direct consequence of the liquid magnesium penetration into the shell. The use of NOVEC 612 led to the formation of the continuous oxide layer on the interface with the thickness up to $60 \mu \mathrm{m}$. The reaction intensity was also strongly depended on the relative position to the surface. There was an important influence of oxygen penetration through the ceramic shell and due to it, there were found no traces of mold-metal reactions in the corner on the inner side of the casting. A thick layer of the reaction products separated from magnesium alloy was formed on the outer side of the same casting. This observation was in the agreement with the results from Cingi [4], who found that there was a strong influence of penetrating oxygen on the mold-metal reaction kinetics. The problem of magnesium penetration into the ceramic shell was also described by Piwonka [5], who concluded that it was caused by the use of fine powder of refractories for the first coat, lowering the permeability of the ceramic shell. However in this work, it could be seen that thicker zircon layer decreased the mold metal reactions intensity nearly to zero.

\section{ACKNOWLEDGEMENTS}

This research was financially supported by project from the Ministry of Industry and Trade No.: FV30305. We also acknowledge CEITEC Nano Research Infrastructure (MEYS CR, 2016-2019) for providing us with access to the SEM devices.

\section{REFERENCES}

[1] KAINER, Karl U. Magnesium alloys and technologies. John Wiley \& Sons, 2006.

[2] Regulation (EU) No 517/2014 of the European Parliament and of the Council of 16 April 2014 on fluorinated greenhouse gases and Repealing regulation (EC) No 842/2006.2014, L150/195, available from: https://eurlex.europa.eu/legal-content/EN/TXT/?uri=CELEX\%3A32014R0517.

[3] NOVEC ${ }^{\text {TM }} 612$ Magnesium protection fluid product information, 3M Company, available from: www.3M.com/novec

[4] CINGI, Celal, et al. Mold-metal reactions in magnesium investment castings. Helsinki University of Technology, 2006.

[5] PIWONKA, T.S. Reactions at the mold-metal interface in investment castings. In 42nd Annual Technical Meeting, Investment Casting Institute. 1994, pp. 1-12. 